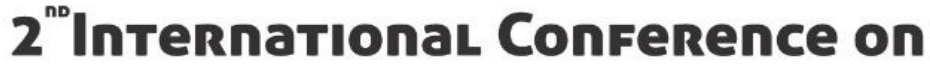 RESEARCH IN HUMANITIES
}

22 - 24 November, 2019 - Paris, France

\section{Material Resistance and Legal Persistence: A Case Study of Hurricane Katrina's Storm Levy Infrastructure and the Katrina Canal Breaches Consolidated Litigation}

\author{
Helen Alexandra Hayes \\ McGill University, Canada
}

\begin{abstract}
Because Hurricane Katrina had such a dramatic effect on the material infrastructure of New Orleans, it can be used as a case study to better understand exactly how and to what extent infrastructure effects social institutions, and also to what extent infrastructure exacerbates the fragile relationships between marginalized communities and the institutions that govern them. Through the analysis of the Katrina Canal Breaches Consolidated Litigation, this research employs the ethnographic and political analysis of disaster infrastructures and their related sociolegal infrastructures to reveal Hurricane Katrina as an essential example of infrastructure failure. In doing so, this paper will reveal how the breakdown of both New Orleans' storm levies and its socio-legal protections (meant to safeguard vulnerable victims of natural disaster) reveal the power of infrastructure to shape social relations, form metonyms of marginality, and produce the conditions for social assembly. To that end, this research draws upon the following concepts: the politics and poetics of infrastructure (Larkin, 2013), the promise of infrastructure (Appel et al., 2018), the ethnography of infrastructure (Star, 1999), and infrastructural resistance (Audette Longo, 2017; Easterling, 2014). By analyzing disaster infrastructures, both material and sociolegal, my research ultimately aims to reveal infrastructures as media of politics - the material sites in or at which we can catch glimpses of what politics is and how it works.
\end{abstract}

Keywords: Law; Hurricane Katrina; Infrastructural Studies; Socio-Legal Studies; Vulnerability

Themes: Infrastructural Breakdown; Marginalization; Victimization; 